\title{
ANÁLISE DAS DEMONSTRAÇÕES CONTÁBEIS PARA CONTRATAÇÃO DE EMPRÉSTIMOS BANCÁRIOS
}

\author{
Sheila Barbosa Praia ${ }^{\mathrm{I}}$ \\ Ian Soares Oliveira ${ }^{2}$ \\ Zuila Paulino Cavalcante ${ }^{3}$
}

RESUMO: O presente estudo vislumbra a necessidade das análises das demonstrações contábeis provindas de suas informações como ferramenta de estudo do Patrimônio, tornando a peça fundamental na tomada de decisões assertivas. A análises das demonstrações contábeis tem por objetivo passar uma visão clara e crítica sobre a situação patrimonial, econômica, e financeira de uma empresa, ajudando os gestores a ter uma melhor perspectiva da situação real em torna da saúde financeira do patrimônio, tornando possível a verificação de que uma das maiores premências de empresas de grandes e pequeno porte é o capital de giro e para obtenção deste recurso comumente utiliza se o crédito empresarial. Desta forma tem se como finalidade descrever o papel das demonstrações contábeis na gestão empresarial, baseando se nas análises das demonstrações contábeis como ferramenta na tomada de decisões. Para a formulação deste artigo, realizou-se uma pesquisa bibliográfica com autores de artigos, livros, normas, e leis que 208 tratam dos procedimentos de análise como fator de avaliação, o estudo aplica esta forma analítica como avaliação para a contratação de empréstimo bancário. Portanto conclui se que é possível identificar os riscos através das análise das demonstrações contábeis aplicadas ao estudo do patrimônio e assim criar uma estratégia que minimize o risco de onerosidade para as empresas, descobrindo o valor de empréstimo necessário e sua melhor aplicação.

Palavras-Chaves: Demonstrações Contábeis. Análise das demonstrações contábeis. Empréstimos.

ABSTRACT: The present study envisions the need for analysis of accounting from of its information as a tool for studying heritage, making it a fundamental part of the tool making assertive decisions. The purpose of the analysis of the accounting accounts is to a clear and critical view of a company's equity, economic and financial situation, helping managers to have

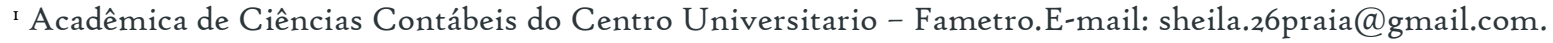

${ }^{2}$ Acadêmico de Ciências Contábeis do Centro Universitario - Fametro.

3 Mestre e Professora do Centro Universitário - Fametro. 
a better perspective of the real situation around financial health equity, making it possible to verify that one of the greatest needs of companies large and small is working capital and to obtain from this common resource business credit. Thus, the role of accounts is defined accounting in business management, based on the analysis of accounting accounts as tool in decision making. For the family in this article, a survey was conducted bibliography with authors of articles, books, rules, and laws dealing with analysis as an evaluation factor, the study applies this analytical form as an evaluation for the bank loan contracting. Therefore, it concludes whether it is possible to identify the risks through the analysis of the accounting accounts applied to the study of equity and thus creating a strategy that minimizes the risk of cost for companies, discovering the value of necessary loan and its best application

Keyword: Accounting statements. Analysis of financial statements. Loans.

\section{INTRODUÇÃO}

O atual momento socioeconômico do país eleva a exigibilidade de controle e estratégias financeiras pelos gestores para que as entidades permaneçam ativas, pois o mundo globalizado permite uma exposição a eventos negativos que afetam o faturamento. A contratação de empréstimos é um dos principais meios de captação de recursos para movimentação de capital de giro, todavia a opção de crédito é possível, porém a o encarecimento das taxas de juros que,

sem um planejamento estratégico, pode vir a comprometer o caixa da empresa, evidenciando assim a importância de conhecer a conjuntura ao qual a organização está inserida.

Os empréstimos podem ser aquisições financeiras ou de bens com o intuito de aplicação para gerar receita. Contudo, a pesquisa se delimita ao estudo para aquisição de empréstimo apenas financeiro, recurso este utilizado para movimentação do capital de giro, que propicia a empresa o pagamento de fornecedores, funcionários e compra de mercadorias e matérias primas, este modelo de empréstimo é principalmente utilizado no início das atividades e durante quando se há um tempo relativamente longo para a liquidação por parte do cliente.

Desta forma, o objetivo desta pesquisa foi demonstrar a importância da análise do patrimônio da empresa através de demonstrações contábeis para a contratação de empréstimos bancários, descrevendo o papel dessas demonstrações para a gestão empresarial diante da tomada de decisões acerca de empréstimos bancários. A pesquisa é de caráter exploratório, levantando problemas e hipóteses, utilizado como método pesquisa bibliográfica abordando os conceitos e normas que tangem tanto a contabilidade quanto os empréstimos, dessa forma foi 
utilizada uma pesquisa qualitativa para a coleta de informações sobre o tema, apresentando conceito de autores e normas, sendo utilizado a análise contábil em estudo hipotético para evidenciar que é necessário utilizar diversos estudos para um aquisição de empréstimo assertiva.

Diante disso serão expostas as características das demonstrações contábeis normatização, aplicação e relevância para as organizações de modo geral, assim como é desenvolvida a fundamentação, conceito e impactos na empresa pela contratação de empréstimo, levando em consideração análise sobre o giro de estoque, índice de endividamento e necessidade de capital de giro.

\section{REFERENCIAL TEÓRICO}

\section{I Demonstrações Contábeis}

$\mathrm{Na}$ atual conjuntura macroeconômica, a globalização tem possibilitado a competitividade de mercado entre empresas de diversos portes e diferentes países, exigindo dos gestores uma posição estratégica e uma visão aguçada de sua área de atuação. Está analise permite o desenvolvimento de um planejamento acerca da captação de recursos, aumento do faturamento e elaboração de novos produtos.

Esta necessidade de visão estratégica por parte dos administradores vai de encontro com o objetivos dos relatórios financeiros fornecidos pela contabilidade que consiste no fornecimento de informações da entidade preservando sua qualidade para atuar como fator determinante nas tomadas de decisões, estes relatórios são formados a partir dos dados do ativo, passivo, patrimônio líquido, receita e despesas registrados no decorrer das atividades diárias da organização, permitindo a formação das demonstrações contábeis.

As demonstrações contábeis são relatórios gerados a partir dos fatos administrativos escriturados pela entidade, ou seja, toda informação econômica, financeira estará demonstrada nessas peças fundamentais da gestão empresarial. Possuem obrigatoriedade de acordo com a lei 6.404/76, Lei 11638/2007, II94I/2009 e CPC 26 (RI) podendo variar da quantidade de demonstrações de acordo com o regime tributário da organização.

O CPC $26\left(\mathrm{R}_{\mathrm{I}}\right)$ normatiza a apresentação das demonstrações contábeis padronizando suas apresentações de modo a melhor atender a análise por parte dos usuários. Segundo Attie 
(2018) as demonstrações precisam expressar clareza de modo a apresentar a real situação da empresa com relação aos seus bens, direitos, obrigações e resultados das operações realizadas, enfatizando para sua elaboração seguindo os princípios contábeis que proporcionam interpretação uniforme e facilidade de compreensão.

Art. $176 \S 4^{\mathrm{o}}$ da lei $6.404 / 76$ determina que a modo de complementação das demonstrações deve ser apresentado também as notas explicativas esclarecendo a situação patrimonial e dos resultados da empresa. Ainda segundo o art. 176 as demonstrações contábeis são compostas por:

Balanço Patrimonial: É composto pela situação financeira, econômica e contábil da empresa com todos os fatos escriturados, permite uma visão macro da entidade. Montoto (2018) descreve que o balanço patrimonial é um importante relatório contábil, pois nele é possível ser apresentado resumidamente os saldos das contas para objeto do estudo do patrimônio, findo as suas alterações no decorrer do exercício concretizando o objetivo geral da contabilidade de acordo com o CPC oo $\left(\mathrm{R}_{2}\right)$.

Demonstração dos Lucros ou Prejuízos Acumulados: Irá evidenciar as alterações ocorridas no patrimônio da empresa. Ferreira (2017) apresenta a DLPA como sendo as variações 211 ocorridas na conta de lucro e prejuízo acumulado no decorrer do exercício de forma abrangente.

Demonstração do Resultado do Exercício: É feito o cruzamento das despesas e receitas da empresa em um determinado período evidenciando seu lucro líquido ao final. Ferreira (2017) define a DRE sendo a exposição ordenada das receitas realizadas e das despesas incorridas no exercício sendo escrituradas de acordo com o regime de competência.

Demonstração do Fluxo de Caixa: Evidencia a posição financeira da entidade, podendo ser feita de forma direta e indireta. Azzolin (2012) enfatiza que a DFC proporciona uma visão futura em consequência dos fatos ocorridos no momento da previsão, tornando-se obrigatória com a lei ir.638/2007.

Demonstração do Valor Adicionado (caso companhia aberta): Mensura o valor da riqueza gerada pela companhia. Montoto (2018) explica que o valor adicionado pode ser calculado pela diferença entre o valor de venda e o custo da mercadoria vendida, desse modo é possível observar a capacidade da empresa em cumprir com suas obrigações. 
Os dados compreendidos nos relatórios contábeis como visto permite que o gestor compreenda de uma forma macro o efeito de suas decisões, para o detalhamento da situação financeira é realizado a utilização de índices para a captação de dados específicos que evidencia a liquidez, endividamento, prazo médio de pagamento e entre outros. Desta forma os usuários de tais informações podem elaborar uma previsão futura de seus ganhos e perdas, este estudo parte da análise das demonstrações contábeis.

Segundo Montoto (2018) refere-se a respeito dos usuários das demonstrações contábeis aqueles que estão direta ou indiretamente sobre a influência dos resultados da entidade, sendo os usuários internos partes integrantes da empresa e usuários externos fornecedores, investidores, agências financeiras, clientes e entre outros. Estes utilizam de forma específica ao seu interesse avaliação das estratégias utilizadas para aumento de lucro e competitividade de mercado.

\subsection{Análise das Demonstrações contábeis}

A análise das demonstrações contábeis, permite uma visão crítica sobre as informações da empresa, seu endividamento, média de giro de estoque, capacidade de pagar os fornecedores

a curto prazo, sua solvência entre outros. A solvência é através do cálculo de quocientes de liquidez evidenciando a capacidade de pagamento em curto e longo prazo pelas entidades (AZZOLINE, 2012). Esse dado contribui para a empresa reconhecer que a condição financeira está em dia. Todas as demonstrações contábeis devem ser analisadas, porém cada demonstração tem sua particularidade e possui informações sobre determinadas operações da empresa, contribuindo para as análises mais específicas de acordo com o interesse do avaliador (SILVA; COUTO e CARDOSO, 2016).

De acordo com Montoto (2018) as análises são referentes às verificações e correspondem às comparações, cálculos, estatísticas, entre outros. Permitindo assim, investigações, ressaltando a comparação entre dois exercícios e avaliando a liquidez existente, prazo médio de renovação de estoque, prazo médio de pagamento de fornecedores, dados estes matemáticos e estatísticos que possibilitam a análise da evolução do patrimônio.

\section{3 Índices}


São indicadores constituídos de fórmulas que extraem das demonstrações contábeis dados específicos que possibilitam avaliar o processo e atuação da entidade em sua área de atuação. Os índices podem variar de acordo com o que interessa a quem está necessitando.

\begin{abstract}
A estrutura contábil tem toda uma sequência ordenada. A partir da coleta dos fatos econômicos e financeiros, registra-se contabilmente esses fatos, levantando as demonstrações contábeis, seguindo-se das técnicas de análise de balanços contemplando as informações para tomada de decisões. Essa cadeia sucessiva de construção de informações econômicas e financeiras tem como objetivo resumir, simplificar e facilitar o excesso de informações contábeis, convertendo-os em indicadores gerenciais (AZZOLIN, 2012, p. 193).
\end{abstract}

Os índices podem ser divididos em quatro grupos: liquidez, operacional, estrutura e rentabilidade. Estes grupos permitem uma melhor avaliação dos fatos contábeis. Pode-se através destes determinar as reais necessidades da entidade.

\title{
A) Índice Liquidez
}

É a forma de identificar o quanto os ativos que a entidade possui pode ser convertido em dinheiro rapidamente e assim pagar suas dívidas. Dessa forma será avaliado tanto os direitos da empresa quanto suas obrigações.

\section{a) Liquidez Seca}

Através desta análise é possível identificar a capacidade de pagamento das dívidas de curto prazo com os ativos circulantes de maior liquidez. Tais ativos são representados pelos bens e direitos com maior capacidade de conversão em dinheiro, sendo composto apenas pelo curto prazo sendo banco, caixa, aplicações automáticas, estoques e entre outros, é descartado por exemplo ativos imobilizados por precisarem de um prazo maior para sua venda e assim tornar-se numerário disponível.

\section{(Ativo Circulante - Estoques)}

\section{Passivo Circulante}

Montoto (2018) explica que esse índice pode ser calculado excluindo os clientes menos líquidos, as despesas antecipadas e estoques, mantendo as contas de maior liquidez como o disponível as aplicações financeiras e os clientes com reais possibilidades de conversão em dinheiro.

\section{b) Liquidez Geral}


A liquidez geral ou total nos possibilita encontrar a situação monetária e de estoque em relação ao total de suas dívidas. Consiste em uma visão ampla onde é avaliando tanto os bens e direitos de curto e longo prazo como as obrigações a curto e longo prazo. Montoto (2018) define a liquidez geral como sendo uma visão geral em que ativos não permanentes podem garantir as dívidas totais, ou seja, os ativos não permanentes irão garantir as dívidas a curto prazo.

\section{Ativo Circulante + Ativo Realizável a Longo Prazo \\ Passivo Circulante + Passivo Exigível a Longo Prazo}

\section{B) Índice Operacional}

Permite uma análise operacional da entidade, medindo fatores determinantes das atividades rotineiras, como prazo médio de estoque, vendas, compra de mercadorias e entre outros.

\section{a) Prazo Médio de Rotação dos Estoques}

Quantidades de dias que a empresa efetua a renovação de todo o seu estoque, este índice contribui para um planejamento assertivo da rotativa e necessidade de compra de novos materiais para o estoque. Montoto (2018) complementa que em caso não se há estoque de início de período, pode-se considerar por aproximação que o estoque se manteve constante durante todo o decorrer do período e é tomado como base o estoque do último exercício.

Estoques $\quad \times 360$

Custo de Vendas Anuais

\section{b) Prazo Médio de Recebimento}

É o tempo médio que em dias da venda até o dia de liquidação do cliente. Este indicador é importante, pois permite que a entidade compreenda se o capital está movimentando, uma empresa em que tem grande rotatividade de estoque mas um tempo longo de recebimento dos clientes está favorável a necessidade de empréstimo, para que se tenha recurso suficiente para pagar fornecedores e fazer novas compras enquanto não recebe o recurso do cliente.

$$
\mathrm{PMR}=\ldots \text { Contas a Receber } \quad \times 360
$$


Receita Líquida

\section{C) Índice de Estrutura}

É possível analisar a estrutura relacionando o capital tanto próprio como terceiros que origina no Passivo em relação aos recursos aplicados que origina do Ativo.

\section{a) Composição do endividamento}

O endividamento financeiro é composto por fornecedores, empréstimos, financiamento. Esses dois últimos em especial são recursos geralmente de longo prazo, para dessa forma a organização tenha tempo hábil para arrecadar recursos para quitação. $O$ índice mais estudado para se ter o reflexo do saldo devedor da empresa é o endividamento geral, por meio dele é possível perceber se é utilizado mais o capital de terceiros ou próprio, quanto maior for o grau de endividamento maior será a alavancagem (GITMAN, 2004). O indicador em questão representa as dívidas da empresa, a quantidade de Capital de Terceiros (CT) que deverá ser quitada a $\mathrm{CP}$ e, consequentemente, a quantidade da própria dívida que deverá ser quitada a LP (DEMICHELI, 2019).

$$
\text { Endividamento Geral }=\frac{\text { Capital de terceiros }(\mathrm{PC}+\mathrm{PNC}) \cdot \mathrm{Ioo} \%}{\text { Capital de terceiros }+ \text { Capital próprio }}
$$

\section{b) Índice de Necessidade de Capital de Giro}

Corresponde a avaliação de necessidade de numerário para as operações da atividade fim, a necessidade de capital de giro (NCG) a diferença entre o ativo circulante cíclico e o passivo circulante cíclico (SILVÉRIO; VICECONTI, 2018). Além disso Montoto (2018) explica que para que uma empresa ceda prazo para seus clientes efetuarem o pagamento é preciso que o pagamento a seus fornecedores seja também a prazo para que primeiro receba e depois pague os fornecedores, neste modelo ela não irá necessitar de significativo capital de giro, mas caso ocorra ao contrário ela precisa de captação de recursos para que seja liquidado suas obrigações até ocorrer o recebimento por parte dos clientes.

NCG = Ativo Circulante Operacional - Passivo Circulante Operacional

\section{D) Índice de Rentabilidade}

\section{a) Rentabilidade das Vendas (Margem Líquida)}


A rentabilidade se difere da lucratividade. Essa última está relacionada aos processos da atividade da entidade, ou seja, é obtido ele através do cálculo das despesas menos receitas elaboradas da demonstração do resultado do exercício, onde neste é possível verificar a composição das despesas e receitas ocorridas no período examinado. Enquanto a rentabilidade está mais relacionada ao retorno do que foi investido, sua eficiência global quanto retornou, de lucro líquido por cada $\mathrm{R} \$ \mathbf{1}, 00$ vendido. Demonstra a efetividade do retorno financeiro da entidade.

\subsection{Empréstimos}

$\mathrm{O}$ atual momento econômico de incertezas em que o Brasil está inserido tende a exigir das empresas abordagens mais estratégicas quanto a sua saúde financeira e resultados que estão atingindo. Esta mudança de posicionamento das entidades tem se mostrado importante. De acordo com o Instituto Brasileiro de Geografia e Estatística - IBGE em 2018 a taxa de sobrevivência das empresas foi de 84,I\% ligeiramente inferior à de 2017 (84,8\%) representando um saldo negativo de 65,9 mil empresas encerradas. Segundo os dados do Banco Central (202I) o crédito ampliado às empresas somou $\mathrm{R} \$ 4,3$ trilhões (57,3\% do PIB) com variação de $\mathrm{I}, \mathrm{I} \%$ no mês e de $18,0 \%$ em doze meses.

Ainda segundo o $\mathrm{BC}$, o Indicador de Custo de Crédito (ICC), apurou uma média nacional de taxa de juros em i7,2\% a.a. e a inadimplência alcançou 2,3\%, crescimento de 0,2 p.p pelas pessoas jurídicas. Diante desses dados, cabe aos gestores avaliarem a necessidade de contratação de empréstimo por parte da empresa e para a tomada de decisão é essencial avaliar a condição financeira da entidade. O pronunciamento técnico CPC 26 Ri destaca que os

objetivos das demonstrações contábeis também são apresentar os resultados da atuação da administração, em face de seus deveres e responsabilidade na gestão diligente dos recursos que lhe foram confiados. Neste estudo será demonstrado o conceito das análises das demonstrações contábeis e dos empréstimos, sua aplicação evidenciando como fator principal para a tomada de decisões da entidade.

O crédito empresarial geralmente é utilizado no início da atividade da organização ou durante para movimentar o capital de giro utilizando um prazo longo para recebimento do numerário. O empréstimo é uma forma de contrato entre uma entidade com a instituição 
financeira que sede a quantia pedida com base em prazo para pagamento de valor original e juros incidentes.

Os empréstimos são formas de captação de recursos firmados através de um contrato em que o banco empresta valores para a empresa, cobrando taxas que serão acrescidas no valor principal pelo benefício concedido, neste caso tratando-se de empréstimo bancário. De acordo com o relatório trimestral de estatística monetária divulgado pelo BACEN em Março de 202I, demonstra o crescimento na captação de crédito por parte das empresas.

Figura I- Operação de Crédito do Sistema Financeiro Nacional

2. Operações de crédito do Sistema Financeiro Nacional (SFN)

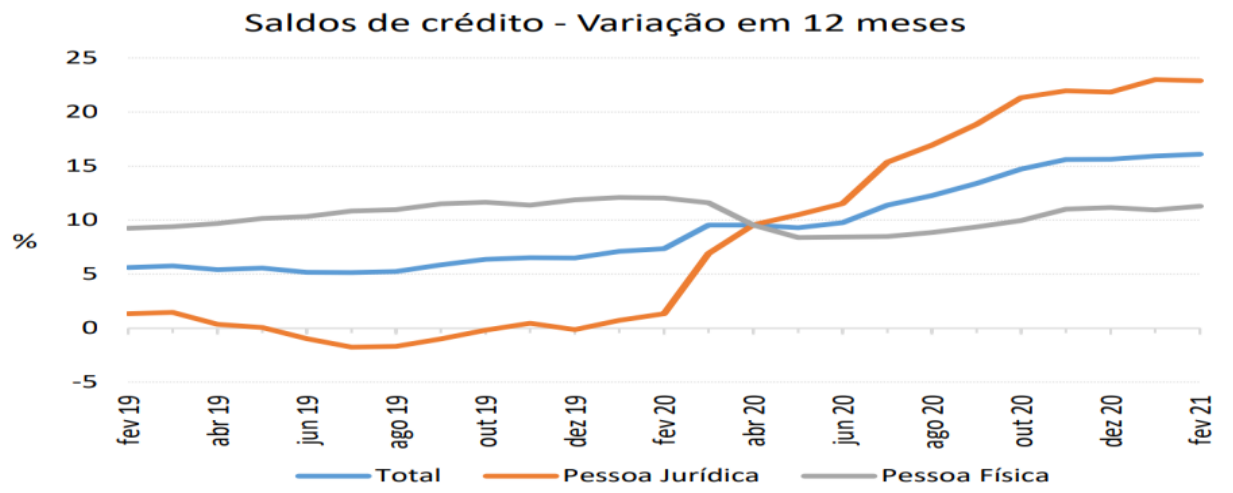

Conforme Ribeiro (2013) existem diferentes tipos de empréstimos, diferindo uns dos outros quanto à forma e ao prazo de pagamento, quanto aos cálculos dos acréscimos como juros, correção monetária e entre outros, que podem ser fixos (pré-fixados) ou variáveis (pósfixados). A diferenciação tem impacto relevante na apuração dos encargos financeiros contratados, desse modo o montante a ser desembolsado para a liquidação poderá ser mais favorável ou não (GELBCKE; SANTOS; IUDÍCIBUS e MARTINS, 2018).

Os créditos pré-fixados possuem seus juros previamente definidos no contrato, permitindo que o contrata saiba no momento do pedido as parcelas e juros que serão pagos dentro do prazo estipulado. Em razão disso a empresa pode registrar apenas o montante das parcelas que serão liquidadas no final do contrato no passivo, enquanto os encargos incidentes são lançados em uma conta redutora de juros a transcorrer, posteriormente no momento de sua 
ocorrência ser transferida para despesa financeira, desse modo o balanço patrimonial irá demonstrar o saldo do empréstimo a valor liquido facilitando o entendimento e também o reconhecimento da obrigação para seus usuários (GELBCKE et.all, 2018).

Em contrapartida, os créditos pós-fixados sofrem alterações em relação aos encargos sobre o recurso, pois irá variar de acordo com o indexador atrelado que geralmente é inflação. GELBCKE et.all, (2018) explica que no contrato pós-fixado o contratante fica exposto às variações econômicas pelo relacionamento dos juros taxa de inflação do país ou por outros indexadores, neste caso por ser volúvel os juros eles não serão reconhecidos desde o início da operação, ocorrendo após a realização do cálculo da taxa de encargos do período.

O processo para a concessão de crédito realizado pelas entidades financeiras parte de garantias que a empresa irá demonstrar provando que pode cumprir com o que foi contratado. Inicialmente é necessário que seja realizado o estudo da real necessidade de crédito, para que não seja contratado nem mais, nem menos que o devido, após encontrar o valor preciso é calculado o custo efetivo total que irá permitir a previsão do total de juros a pagar assim como o prazo para pagamento.

Posterior a previsão do custo do crédito é necessário a elaboração do plano de negócio 218 que apresentará de forma objetiva o setor da empresa e seu estudo para a captação de crédito e seu retorno. Após o planejamento é preciso apresentação da documentação para solicitação do empréstimo, que consiste em:

I. Cadastro de todos os sócios e cônjuges

2. CNPJ Atualizado

3. Contrato Social

4. Ata de constituição

5. Estatuto ou declaração de empresário

6. Alterações Contratuais

7. Balanço Patrimonial

8. Demonstração do Resultado do Exercício

9. Autorização Para Consulta ao SISBACEN

Io. Escritura dos bens Imóveis 
Após feita solicitação do empréstimo com a documentação a entidade financeira irá realizar uma análise de crédito as entidades utilizam critérios de riscos conhecidos como seis Cs:

- Caráter: Avalia o histórico de pagamentos da entidade.

- Capacidade: Analisa a situação líquida da empresa e sua capacidade de pagamento.

- Capital: É feito o levantamento dos bens que a empresa poderá estar vendendo para pagamento das dívidas.

- Conglomerado: São operações realizadas entre a empresa física e jurídica.

- Condições: Verifica-se o setor ao qual a entidade está inserida.

- Colaterais: É apresentado as garantias formas para realização da operação.

Portanto é possível compreender que existe uma série de documentos que buscam comprovar a veracidade dos dados apresentados, comprovando que a simples suposição de valor sem uma avaliação analítica expõe de forma arriscada o capital da entidade, pois a contratação de empréstimo a maior ou a menor irá gerar uma onerosidade com relação prejudicial com encargos e a prestação mensal a ser paga. Portanto, ressalta-se a importância da análise das 219 demonstrações contábeis para avaliação da situação financeira e retorno das vendas para uma decisão menos onerosa e que permitirá um retorno diante do investimento concedido com o crédito contratado, pois a análise irá permitir compreender o valor da necessidade de capital de giro a ser pedido, o atual retorno das vendas, a rotatividade do estoque, prazo de liquidação dos clientes, entre outros.

\section{CASO HIPOTÉTICO}

O caso hipotético foi desenvolvido para aplicação dos índices estudado, dessa forma foi utilizado o estudo com base no Balanço Patrimonial e Demonstração do Resultado do Exercício.

A entidade Bolinhas S.A é voltada para a atividade de fabricação e comercialização de bolas festivas de plásticos, muito utilizadas nos parques temáticos, ela instalou-se no polo industrial de Manaus- AM há 2 anos e desde então vem obtendo lucros. Em seu último exercício verificou-se a possibilidade de expansão e crescimento, para isso foi sugerido a contratação de 
empréstimo para aumento do capital de giro. Desta forma foi realizada uma análise das demonstrações contábeis com o objetivo de observar onde o recurso será melhor aplicado e qual o valor necessário a ser pedido sem que a empresa termine prejudicada no final do contrato.

\section{TABELA oI- BALANÇO PATRIMONIAL}

BALANÇO PATRIMONIAL

\begin{tabular}{|l|l|l|l|}
\hline Ativo Circulante & $\mathrm{R} \$ 422.000,00$ & Passivo Circulante & $\mathrm{R} \$ 355.500,00$ \\
\hline Disponibilidades & $\mathrm{R} \$ 156.000,00$ & Fornecedores & $\mathrm{R} \$ 300.000,00$ \\
\hline Duplicadas a receber & $\mathrm{R} \$ 26.000,00$ & Contas a pagar & $\mathrm{R} \$ 55.500,00$ \\
\hline (-) Prov.dev.duvid. & $-\mathrm{R} \$ 11.000,00$ & Passivo não circulante & $\mathrm{R} \$ 206.000,00$ \\
\hline Estoques & $\mathrm{R} \$ 251.000,00$ & Financiamentos Internos & $\mathrm{R} \$ 78.000,00$ \\
\hline Ativo Não Circulante & $\mathrm{R} \$ 420.000,00$ & Financiamentos & $\mathrm{R} \$ 128.000,00$ \\
\hline Duplicatas a receber & $\mathrm{R} \$ 29.000,00$ & Patrimônio Líquido & $\mathrm{R} \$ 280.500,00$ \\
\hline Imobilizado & $\mathrm{R} \$ 391.000,00$ & Capital Social & $\mathrm{R} \$ 280.500,00$ \\
\hline Ativo Total & $\mathrm{R} \$ 842.000,00$ & Passivo Total & $\mathrm{R} \$ 842.000,00$ \\
\hline
\end{tabular}

A demonstração contábil contábil da empresa Bolinhas S.A irá permitir a avaliação necessária a qual os gestores estão precisando. Iniciando a sua análise obtemos através do índice de liquidez seca obtemos:

\section{Índice de Liquidez Seca}

$$
\underline{(422.000,00-251.000,00)}
$$

$355 \cdot 500,00$

Índice de liquidez Seca $=0,48$ 
Através desse resultado é possível identificar que a Bolinhas S.A possui no curto prazo mais dívida do que receita, pois para cada $\mathrm{R} \$ \mathbf{1} .00$ de dívida ela tem $\mathrm{R} \$ 0,48$ de receita. É importante enfatizar que esse índice possui como fator de cálculo as contas de maior liquidez, ou seja, caixa e equivalentes de caixa, excluindo dessa forma a utilização de imobilizado e ativos de longo prazo e baixa liquidez.

\section{Índice de Liquidez Geral}

Para se obter uma visão ampla em relação a capacidade de pagamento das dívidas será utilizado o índice de liquidez geral.

422.000,00 + 420.000,00

$355 \cdot 500,00+206.000,00$

Índice de Liquidez Geral= o,8o

Desse modo podemos verificar que apesar da liquidez seca estar baixa, de modo geral a empresa é possível pagar mais da metade das dívidas existentes, mesmo sendo abaixo do total das obrigações, através deste é possível compreender que a análise não pode conter apenas um índice como fator de decisão, mas vários, permitindo uma visão crítica.

\section{Necessidade de Capital de Giro.}

Ao ser realizado o índice da necessidade de capital de giro chegamos ao resultado que é a entidade precisaria de $\mathrm{R} \$ 66.500,00$. Esse resultado importante saber pois ele nos passa a previsão de capital que a entidade necessita.

\section{Índice de Endividamento}

Diante do exposto foi pesquisado seu percentual de endividamento, para que o gestor possa entender o quanto as obrigações podem comprometer no processo de crescimento.

$$
355 \cdot 500,00+206.000,00 \cdot 100 \%
$$

$355 \cdot 500,00$

Endividamento $=63,31 \%$

Este chegando a 63,31\%. Nota-se um ponto de atenção por se ter uma dívida maior que a quantidade de bens e direitos, ao se analisar sua necessidade de capital de giro é apresentado o valor de $\mathrm{R} \$ 77.500,00$ para a continuidade de suas atividades e consequente aumento de faturamento. 


\begin{tabular}{|l|l|l|}
\hline DESCRITORES & X2 & XI \\
\hline Estoques de Mercadorias & $\mathrm{R} \$ 550,00$ & $\mathrm{R} \$ 700,00$ \\
\hline $\begin{array}{l}\text { Custo das Mercadorias } \\
\text { Vendidas }\end{array}$ & $\mathrm{R} \$ \mathrm{I} .400,00$ & $\mathrm{R} \$ 3.800,00$ \\
\hline Duplicatas a receber & $\mathrm{R} \$ 800,00$ & $\mathrm{R} \$ 700,00$ \\
\hline Duplicatas a pagar & $\mathrm{R} \$ \mathrm{I} .400,00$ & $\mathrm{R} \$ 2.300,00$ \\
\hline Vendas a prazo & $\mathrm{R} \$ 3.700,00$ & $\mathrm{R} \$ 9.000,00$ \\
\hline Compras & $\mathrm{R} \$ 2.900,00$ & $\mathrm{R} \$ 5.500,00$ \\
\hline
\end{tabular}

Fonte: elaboração dos autores.

O estoque é o principal setor que gera uma grande quantidade de custo para as entidades de modo geral, por estar exposto a diversas variáveis, este pode compor grande parte do custo e despesa, é através dele que será armazenado a matéria prima ou o produto a ser revendido.

\section{Rotatividade do Estoque}

Considerando-se seu estoque foi encontrado uma média de 88 dias de renovação de estoque, fator preocupante que demonstra uma pequena saída de mercadorias, elevando seu 222 custo de armazenamento e atrasando a entrada de novos produtos que podem ser mais competitivos no mercado.

\section{Prazo Médio de Recebimento}

Nota-se que esta pequena saída acompanha um longo prazo para recebimento de seus clientes, ao ser avaliado o prazo médio de recebimento de duplicatas é identificado a média de 75 dias. Portanto a empresa possui uma estratégia que evita o aumento das dívidas, ela recebe antes

da entrada média de produtos. Este é um ponto importante, pois uma entidade sem capital de giro não teria esse fluxo de recebimento, o que permite reconhecer que a empresa tem tido um fluxo suficiente para manter as suas necessidades, no entanto, como demonstrado nos indicadores anteriores é possível observar que não se tem um retorno significativo da atividade fim, que seja possível o aumento de suas operações, nos remetendo que a organização está girando seus recursos apenas de forma suficiente. 


\section{DEMONSTRAÇÃO DO RESULTADO DO EXERCÍCIO}

\begin{tabular}{|l|l|}
\hline Receita Bruta de Vendas & $\mathrm{R} \$ 72.546,56$ \\
\hline Custo dos Produtos Vendidos & $-\mathrm{R} \$ 18.435,28$ \\
\hline Lucro Bruto Operacional & $\mathrm{R} \$ 54.111,28$ \\
\hline Despesas Operacionais & $\mathrm{R} \$ 6.650,00$ \\
\hline Despesas com Vendas & $\mathrm{R} \$ 1.000,00$ \\
\hline Despesas Gerais e Administrativas & $\mathrm{R} \$ 870,00$ \\
\hline Despesas de Aluguel & $\mathrm{R} \$ 487,00$ \\
\hline Despesas Financeiras & $\mathrm{R} \$ 596,00$ \\
\hline $\begin{array}{l}\text { Lucro antes dos Tributos sobre } \\
\text { Resultado }\end{array}$ & $\mathrm{R} \$ 44.508,28$ \\
\hline IRPJ e CSLL & $\mathrm{R} \$ 6.676,24$ \\
\hline Lucro Líquido do Exercício & $\mathrm{R} \$ 37.832,04$ \\
\hline
\end{tabular}

Fonte: elaboração dos autores.

Rentabilidade das Vendas

Ao ser revisado a DRE é notado que para cada venda a empresa possui um total de $\mathrm{R} \$$ 0,52 de lucro líquido, ou seja para cada $\mathrm{R}_{\$}$ I,oo vendido a empresa possui pouco mais de 50\% de lucro, um valor de retorno abaixo do esperado, demonstrando que com o que recebe das vendas gera pouco capital para investimento e aumento da competitividade no mercado.

\section{CONCLUSÃO}

Este trabalho teve como objetivo realizar a análise a respeito das demonstrações contábeis para a contratação de empréstimos bancários, desta forma evidenciando a necessidade do planejamento com base em uma revisão bibliográfica. A partir de textos, dissertações, livros, artigos para a melhor compreensão, e assim, fazendo com que fosse possível o aprendizado sobre o tema abordado, analisando contabilmente a tomada de empréstimos em um estudo hipotético.

O estudo hipotético apresenta como as informações registradas pela contabilidade fica disposta em seus relatórios e como é realizado sua avaliação através das demonstrações 
apresentadas a aplicação das análises das demonstrações contábeis e o que pode ser interpretado diante dos resultados obtidos, como demonstrado é possível compreender detalhadamente os principais campos da entidade, seu fluxo, seu retorno financeiro, prazos e entre outros, dados essenciais para a captação de recursos de forma estratégica sem que prejudique a entidade.

Diante disto é possível compreender as demonstrações contábeis como relatórios obrigatórios e de extremo valor para o desenvolvimento das empresas, pois está registrado todos os fatos ocorridos, de forma que contribua para sua interpretação, com dados comparativos possibilitando uma previsão de ocorrências futuras.

Desta forma a análise das demonstrações atua como ferramenta de interpretação detalhada desses relatórios extraindo informações de maneira fácil e ágil que permite avaliar os processos ocorridos. Essa análise consiste da aplicação de índices que pode variar de acordo com o objetivo do estudo do relatório, como demonstrado no caso hipotético é possível averiguar prazos, rotatividade de mercadorias, retorno financeiro e valor necessário para a necessidade de capital de giro, está tratativa de forma separada pode levar a decisões equivocadas, pois um fato está ligado a outro, o estudo em conjunto permite a comparabilidade e o conhecimento da saúde financeira da entidade.

Sendo assim, foi de extrema importância a realização desta pesquisa, pois possibilitou o entendimento a respeito das demonstrações contábeis e suas estruturas, e toda sua avaliação a partir da análise de seus planejamentos, e assim através do caso hipotético e suas tabelas para o esclarecimento e melhor visualização de cada tópico a ser observado, desta forma de valor acadêmico para que novas pesquisas possam ser realizadas com este suporte e assim ampliando conhecimento para a Contabilidade.

\section{REFERÊNCIAS BIBLIOGRÁFICAS}

AZZOLIN, José. Análise das Demonstrações Contábeis. IEDES Brasil S.A, 2012

ATTIE, William. Auditoria: conceitos e aplicações. 7. ed. São Paulo: Atlas, 2018.

Comitê de Pronunciamentos Contábeis. Pronunciamentos Contábeis. Disponível em: http://www.cpcp.org.br/CPC/Documentos-Emitidos/Pronunciamentos/.Acesso em: 25 de Março de 202I. 
DEMICHELI, DAUANI. Análise das demonstrações contábeis como instrumento de avaliação da situação econômico-financeira: estudo comparativo entre duas empresas do segmento de seguros listadas na Bovespa. Universidade de Caxias do sul. Disponível em: https://repositorio.ucs.br/II338/5095. Acesso em 25 de março de 2021.

GELBCKE, Ernesto Rubens... [et al.]. Manual de Contabilidade Societária: Aplicável a todas as sociedades: de Acordo com as Normas Internacionais e do CPC. 3.ed. São Paulo: Atlas, 2018.

Lei № 6.404, de 15 de dezembro de 1976. Lei das Sociedades por Ações. Disponível em: http://www.planalto.gov.br/ccivil_03/leis/16404compilada.htm. Acesso em 20 de março de 2021.

MARITINI, Lílian Dalamico. Análise do Impacto do Desconto de Duplicatas e Dos Empréstimos no Capital de Giro de Curto a Longo Prazo em uma Vinícola da Serra Gaúcha. Disponível em: https://repositorio.ucs.br/I1338/5618. Acesso em 30 de Março de 2021.

MONTOTO, Eugenio. Contabilidade geral e avançada esquematizado. 5. ed. São Paulo: Saraiva Educação, 2018.

PAULO, Viceconti, Silvério das Neves. Contabilidade Avançada e Análise das Demonstrações Financeiras.18.Ed. São Paulo: Saraiva Educação, 2018.

Ribeiro. Contabilidade Básica Fácil. 29.ed. São Paulo: Saraiva,2013.

SILVA, Michele Prata da; COUTO, Carlos Henrique da Mota; CARDOSO, Antônio Augusto Brion. Análise das Demonstrações Contábeis como Ferramenta de Suporte à Gestão Financeira. 